\title{
Authors' Reply: Risk Factors for Mortality and Morbidity in Elderly Patients Presenting with Digestive Surgical Emergencies
}

\author{
Hassen Hentati ${ }^{1}$ Chetana Lim ${ }^{1} \cdot$ Chady Salloum $^{1} \cdot$ Daniel Azoulay $^{1}$
}

Published online: 8 June 2018

(C) Société Internationale de Chirurgie 2018

We thank Li et al. for their interest to our article recently published in the World Journal of Surgery [1]. We agree that our study includes several limitations that we have already mentioned in the discussion section.

First, we used $12 \mathrm{~g} / \mathrm{dL}$ as the cutoff value of preoperative hemoglobin level. This is the lower limit which was defined by the local laboratory at our institution.

Second, as for the statistical analysis, we performed multivariate binary logistic regression model. We deliberately published the final results of the analysis.

Finally, we agree that scores including intra-operative variables, such as Surgical Apgar Score, Surgical Risk Score, E-POSSUM, APACHE II score and others, are of utmost importance and could predict postoperative morbidity and mortality. However, as already mentioned in the discussion section, we did not use these scores in our study since they include perioperative variables, and therefore, they do not aid a given patient in making the decision on whether to accept or decline emergent surgery. Therefore, we only analyzed preoperative variables in the present study to achieve the study's objective (i.e., to identify preoperative predictors of postoperative mortality and morbidity), which may help the surgical team in making the decision on whether to perform or avoid futile surgery.

\section{Compliance with Ethical Standards}

Conflict of interest The authors declare that they have no conflict of interest.

\section{Reference}

1. Hentati H, Salloum C, Caillet P et al (2018) Risk factors for mortality and morbidity in elderly patients presenting with digestive surgical emergencies. World J Surg. https://doi.org/10. 1007/s00268-017-4419-3
Daniel Azoulay

daniel.azoulay@aphp.fr

1 Department of Hepatobiliary and Pancreatic Surgery and Liver Transplantation, Henri Mondor Hospital, 51 avenue de Lattre de Tassigny, 94010 Créteil, France 